\title{
Pola trauma tumpul toraks non penetrans, penanganan, dan hasil akhir di Instalasi Rawat Darurat Bedah RSUP Prof. Dr. R. D. Kandou Manado periode Januari 2014 - Juni 2016
}

\author{
${ }^{1}$ Kevin G. Pitojo \\ ${ }^{2}$ Adrian Tangkilisan \\ ${ }^{2}$ Alwin Monoarfa \\ ${ }^{1}$ Kandidat Skripsi Fakultas Kedokteran Universitas Sam Ratulangi Manado \\ ${ }^{2}$ Bagian Bedah Fakultas Kedokteran Universitas Sam Ratulangi Manado \\ Email: kevin.pitojo@icloud.com
}

\begin{abstract}
Trauma is reported as the main cause of death, hospitalization, and long-term disability. Blunt thoracic trauma is a common problem in society which can be caused by traffic accidents, fallen from height, impact, and others. This study was aimed to obtain the profile of non-enetrating blunt thoracic trauma in surgery emergency unit of Prof. Dr. R. D. Kandou General Hospital Manado from January 2014 to June 2016. This was a retrospective descriptive study using all medical records of non-penetrating blunt thoracic trauma. The results showed that there were 35 cases of non penetrating blunt thoracic trauma out of a total of 120 cases. The majority of cases occurred in 2014 and 2016 (37.1\%); age group 2130 years $(28.5 \%)$, and males $(85.7 \%)$. The most common cause was traffic accidents $(74.2 \%)$ meanwhile most treatment performed was conservative treatment $(77.1 \%)$ and the outcome of most non-penetrating blunt thoracic trauma was uncomplicated $(77.1 \%)$.
\end{abstract}

Keywords: trauma, blunt thoracic trauma

\begin{abstract}
Abstrak: Trauma dilaporkan menjadi penyebab utama kematian, perawatan di rumah sakit dan kecacatan jangka panjang. Trauma tumpul toraks merupakan masalah umum bagi masyarakat, yang bisa disebabkan oleh kecelakaan lalu lintas, jatuh dari ketinggian, benturan, dan lain-lain. Penelitian ini bertujuan untuk mendapatkan data tentang trauma tumpul toraks non penetrans di IRDB RSU Prof Dr. R. D. Kandou Manado periode Januari 2014-Juni 2016. Jenis penelitian ialah deskriptif retrospektif dengan menggunakan semua data rekam medik pasien trauma tumpul toraks non-penetrans. Hasil peneltiian mendapatkan jumlah kasus trauma tumpul toraks non penetrans sebanyak 35 pasien dari total 120 pasien dengan kasus terbanyak terjadi pada tahun 2014 dan 2016 (37,1\%), kelompok usia 21-30 tahun $(28,5 \%)$, dan jenis kelamin laki-laki $(85,7 \%)$. Penyebab tersering ialah kecelakaan lalu lintas $(74,2 \%)$ sedangkan penanganan yang paling banyak dilakukan ialah penanganan konservatif $(77,1 \%)$. Hasil akhir trauma tumpul toraks non-penetrans yang didapat umumnya tanpa komplikasi $(77,1 \%)$.
\end{abstract}

Kata kunci: trauma, trauma tumpul

Trauma adalah kejadian yang bersifat holistik dan menyebabkan hilangnya produktivitas seseorang. Dewasa ini trauma melanda dunia bagaikan wabah karena dalam kehidupan modern penggunaan kendaraan automotif semakin luas. ${ }^{1}$ Trauma juga dilaporkan menjadi penyebab utama kematian, perawatan di rumah sakit, dan kecacatan jangka panjang dalam empat dekade pertama kehidupan. ${ }^{2}$

Trauma toraks adalah luka atau cedera yang mengenai rongga toraks atau dada yang dapat menyebabkan kerusakan pada dinding toraks ataupun isi dari cavum 
thoraks (rongga dada) yang disebabkan oleh benda tajam atau tumpul dan dapat menyebabkan keadaan sakit pada dada. ${ }^{3}$ Trauma toraks merupakan penyebab kematian utama pada kelompok umur dibawah 35 tahun. Trauma toraks terjadi hampir 50\% dari seluruh kasus kecelakaan.

$20-25 \%$ dari kasus trauma yang diterima rumah sakit berkaitan dengan kematian. Di Indonesia, trauma merupakan penyebab kematian nomor empat, tetapi pada kelompok umur 15-25 tahun, trauma merupakan penyebab kematian utama. Trauma dada kebanyakan disebabkan oleh kecelakaan lalu lintas yang umumnya berupa trauma tumpul $(90 \%){ }^{4}$

Secara garis besar, trauma toraks diklasifikasikan menjadi dua, yaitu trauma tumpul toraks dan trauma tembus toraks. Trauma tumpul toraks biasanya disebabkan oleh karena kecelakaan lalu lintas, sedangkan trauma tembus toraks disebabkan oleh karena trauma tajam (tusukan benda tajam), trauma tembak (akibat tembakan), dan trauma tumpul tembus dada. ${ }^{3}$

Trauma tumpul toraks merupakan masalah yang cukup penting di Indonesia yang harus disikapi dengan serius mengingat akan bahayanya efek penekanan pada struktur-struktur sekitar yang dapat menyebabkan obstruksi jalan napas dan resiko kematian apabila trauma tersebut berkembang menjadi kanker. ${ }^{4}$

Di Asia memiliki angka kematian trauma tertinggi di seluruh dunia, berdasarkan World Health Organization (WHO) angka kematian pada tahun 2008 mencapai $90 \%$ dari seluruh kematian di dunia disebabkan oleh trauma toraks. Trauma toraks semakin meningkat sesuai dengan kemajuan transportasi dan kondisi sosial ekonomi masyarakat. Data yang akurat mengenai trauma toraks di Indonesia belum pernah diteliti. Di Bagian Bedah FKUI/RSUPNCM pada tahun 1981 didapatkan $20 \%$ dari pasien trauma mengenai trauma toraks. ${ }^{5}$

\section{METODE PENELITIAN}

Penelitian ini merupakan penelitian deskriptif yang bersifat retrospektif pada pasien trauma tumpul toraks non penetrans di Instalasi Rawat Darurat Bedah RSU Prof. R. D. Kandou Manado. Subjek penelitian ialah semua data rekam medik pasien trauma tumpul toraks non penetrans di IRDB RSU Prof. Dr. R. D. Kandou Manado periode Januari 2014-Juni 2016. Variabel penelitian yang diteliti adalah tahun, usia, gender, etiologi, penanganan, dan hasil akhir.

\section{HASIL PENELITIAN}

Berdasarkan hasil penelitian yang telah dilakukan dengan cara mengambil data sekunder (rekam medik) pasien trauma tumpul toraks penetrans di IRDB RSU Prof. Dr. R. D. Kandou Manado periode Januari 2014 sampai Juni 2016 diperoleh jumlah pasien sebanyak 35 pasien trauma tumpul toraks non penetrans dari total 120 pasien trauma toraks.

\section{Distribusi trauma tumpul toraks non penetrans berdasarkan tahun}

Dari total 35 pasien trauma tumpul toraks di IRDB RSU Prof. DR. R. D. Kandou Manado periode Januari 2014 sampai Juni 2016, didapatkan pada tahun 2014 sebanyak 13 orang $(37,1 \%)$, tahun 2015 sebanyak 9 orang $(25,7 \%)$, dan tahun 2016 sebanyak 13 orang $(37,1 \%)$.

Tabel 1. Distribusi trauma tumpul toraks non penetrans berdasarkan tahun

\begin{tabular}{ccc}
\hline Tahun & $\begin{array}{c}\text { Kasus trauma } \\
\text { tumpul toraks } \\
\text { non penetrans }\end{array}$ & $\begin{array}{c}\text { Total kasus } \\
\text { trauma toraks }\end{array}$ \\
\hline 2014 & $13(37,1 \%)$ & $16(13,3 \%)$ \\
2015 & $9(25,7 \%)$ & $65(54,1 \%)$ \\
2016 & $13(37,1 \%)$ & $39(32,5 \%)$ \\
Total & $35(100 \%)$ & $120(100 \%)$ \\
\hline
\end{tabular}

Distribusi trauma tumpul toraks non penetrans berdasarkan kelompok usia

Berdasarkan usia dari total 35 pasien, didapatkan kelompok usia antara 0-10 tahun sebanyak 1 orang $(2,8 \%)$, antara 11 20 tahun sebanyak 9 orang $(25,7 \%)$, antara 21-30 tahun sebanyak 10 orang $(28,5 \%)$, antara 31-40 tahun sebanyak 3 orang 
$(8,5 \%)$, antara 41-50 sebanyak 5 orang $(14,2 \%)$, dan 50 tahun ke atas sebanyak 7 orang $(20 \%)$.

Tabel 2. Distribusi trauma tumpul toraks non penetrans berdasarkan kelompok usia

\begin{tabular}{ccc}
\hline $\begin{array}{c}\text { Kelompok } \\
\text { usia } \\
\text { (tahun) }\end{array}$ & $\begin{array}{c}\text { Jumlah } \\
\text { kasus } \\
\text { (orang) }\end{array}$ & $(\boldsymbol{\%})$ \\
\hline $0-10$ & 1 & 2,8 \\
$11-20$ & 9 & 25,7 \\
$21-30$ & 10 & 28,5 \\
$31-40$ & 3 & 8,5 \\
$41-50$ & 5 & 14,2 \\
$>50$ & 7 & 20 \\
Total & 35 & 100 \\
\hline
\end{tabular}

Distribusi trauma tumpul toraks non penetrans berdasarkan gender

Dari total 35 pasien, terdapat sebanyak 30 orang laki-laki (86\%) dan 5 orang perempuan (14\%).

Tabel 3. Distribusi trauma tumpul toraks non trauma berdasarkan gender

\begin{tabular}{cccc}
\hline \multirow{2}{*}{ Tahun } & \multicolumn{2}{c}{ Jenis Kelamin } & \multirow{2}{*}{ Total } \\
\cline { 2 - 3 } & Laki-laki & Perempuan & \\
\hline 2014 & $11(85 \%)$ & $2(15 \%)$ & $13(37 \%)$ \\
2015 & $8(89 \%)$ & $1(11 \%)$ & $9(26 \%)$ \\
2016 & $11(85 \%)$ & $2(15 \%)$ & $13(37 \%)$ \\
Total & $30(86 \%)$ & $5(14 \%)$ & $35(100 \%)$ \\
\hline
\end{tabular}

Distribusi trauma tumpul toraks non penetrans berdasarkan etiologi

Tabel 4. Distribusi trauma tumpul toraks non trauma berdasarkan etiologi

\begin{tabular}{ccc}
\hline Etiologi & $\begin{array}{c}\text { Jumlah kasus } \\
\text { (orang) }\end{array}$ & $(\boldsymbol{\%})$ \\
\hline KLL & 26 & 74,2 \\
Jatuh dari & 5 & 14,2 \\
Ketinggian & 2 & 5,7 \\
Benturan & 2 & 5,7 \\
Tidak Diketahui & 35 & 100 \\
Total &
\end{tabular}

Berdasarkan total 35 pasien trauma tumpul toraks didapatkan penyebab trauma karena KLL sebanyak 26 orang $(74,2 \%)$, jatuh dari ketinggian sebanyak 5 orang $(14,2 \%)$, benturan sebanyak 2 orang $(5,7 \%)$, dan untuk penyebab yang tidak diketahui sebanyak 2 orang $(5,7 \%)$ (Tabel 4).

Distribusi trauma tumpul toraks non penetrans berdasarkan penanganan yang diberikan

Berdasarkan penanganan yang diberikan di RSUP Prof DR. R. D. Kandou Manado dari total 35 pasien didapatkan penanganan konservatif sebanyak 33 orang $(77,1 \%)$, dan penanganan operatif sebanyak 5 orang $(22,8 \%)$.

Tabel 5. Distribusi trauma tumpul toraks non penetrans berdasarkan penanganan yang diberikan

\begin{tabular}{ccc}
\hline Penanganan & Jumlah kasus & $(\boldsymbol{\%})$ \\
\hline Konservatif & 27 & 77,1 \\
Operatif & 8 & 22,8 \\
Total & 35 & 100 \\
\hline
\end{tabular}

Distribusi trauma tumpul toraks non penetrans berdasarkan hasil akhir yang didapat

Berdasarkan hasil akhir yang didapat di RSUP Prof DR. R. D. Kandou Manado dari total 35 pasien ditemukan hasil akhir setelah perawatan, 4 pasien $(11,4 \%)$ mengalami fraktur iga, 2 pasien $(5,7 \%)$ mengalami hemotoraks, dan 2 pasien $(5,7 \%)$ meninggal, sedangkan 27 pasien $(77,1 \%)$ lainnya tidak mengalami komplikasi.

Tabel 6. Distribusi trauma tumpul toraks non penetrans berdasarkan hasil akhir yang didapat

\begin{tabular}{ccc}
\hline Hasil Akhir & $\begin{array}{c}\text { Jumlah kasus } \\
\text { (orang) }\end{array}$ & $\mathbf{( \% )}$ \\
\hline Tanpa komplikasi & 27 & 77,1 \\
Fraktur iga & 4 & 11,4 \\
Hemotoraks & 2 & 5,7 \\
Meninggal & 2 & 5,7 \\
Total & 35 & 100 \\
\hline
\end{tabular}

\section{BAHASAN}

Dari data pasien hasil penelitian mengenai pola pasien trauma tumpul toraks 
non penetrans, penanganan, dan hasil akhir di Instalasi Rawat Darurat Bedah RSU Prof. DR. R. D. Kandou Manado periode Januari 2014 sampai Juni 2016 didapatkan pasien trauma tumpul toraks sebanyak 35 pasien dari 120 pasien trauma toraks, dengan distribusi trauma tembus toraks berdasarkan tahun didapatkan pada tahun 2014 sebanyak 13 orang $(37,1 \%)$, tahun 2015 sebanyak 9 orang $(25,7 \%)$, tahun 2016 sebanyak 13 orang $(37,1 \%)$. Data ini menunjukkan bahwa kasus trauma tumpul toraks non penetrans banyak terjadi pada tahun 2014 dan 2016 dengan jumlah kasus sebanyak 13 orang $(37,1 \%)$ diikuti tahun 2015 sebanyak 9 orang $(25,7 \%)$.

Berdasarkan data hasil penelitian, distribusi trauma tumpul toraks non penetrans didapatkan mayoritas pasien trauma tumpul toraks non penetrans berusia antara 21-30 tahun sebanyak 10 orang (28,5 $\%)$, yang diikuti dengan pasien yang berusia antara 11-20 tahun sebanyak 9 orang $(25,7 \%)$, kemudian 50 tahun ke atas sebanyak 7 orang (20\%), kemudian antara 41-50 tahun sebanyak 5 orang $(14,2 \%)$, kemudian antara 31-40 tahun sebanyak 3 orang $(8,5 \%)$, dan antara 0-10 tahun sebanyak 1 orang $(2,8 \%)$. Hal ini ditunjang sesuai data kepustakaan yang menyatakan bahwa trauma dada merupakan penyebab kematian utama pada kelompok usia dibawah 35 tahun. Di Indonesia trauma menjadi penyebab kematian utama pada kelompok usia 15-25 tahun. ${ }^{4}$

Dari data hasil penelitian, distribusi trauma tumpul toraks non penetrans berdasarkan gender, dari total 35 pasien, pada laki-laki didapatkan sebanyak 30 orang $(85,7 \%)$ dan pada perempuan sebanyak 5 orang $(14,2 \%)$. Berdasarkan etiologi yang paling sering terjadi, laki-laki memiliki risiko lebih tinggi mengalami KLL dibandingkan perempuan. Hal ini dikarenakan mobilitas jenis kelamin lakilaki lebih tinggi daripada jenis kelamin perempuan di jalan raya dalam berkendara. Selain itu jumlah pengguna sepeda motor lebih tinggi pada jenis kelamin laki-laki daripada perempuan. ${ }^{6}$

Untuk distribusi trauma tumpul toraks non penetrans berdasarkan etiologi, total 35 pasien trauma tumpul toraks maka didapatkan penyebab utama trauma karena KLL (74,2\%). Keadaan ini sesuai dengan kepustakaan bahwa sekitar 70\%-80\% kasus trauma merupakan trauma tumpul dan terjadi akibat kecelakaan lalu lintas.

Untuk distribusi trauma tumpul toraks non penetrans berdasarkan penanganan yang diberikan di RSUP Prof DR. R. D. Kandou Manado dari total 35 pasien didapatkan penanganan konservatif sebanyak 27 orang $(77,1 \%)$, dan penanganan operatif sebanyak 8 orang $(22,8 \%)$. Hal ini sesuai dengan kepustakaan yang menyebutkan bahwa hanya 15\%-30\% penderita trauma tumpul toraks yang memerlukan tindakan operasi, jadi sebagian besar hanya memerlukan tindakan sederhana. ${ }^{5}$

Untuk distribusi trauma tumpul toraks non penetrans berdasarkan hasil akhir yang didapat di RSU Prof DR. R. D. Kandou Manado dari total 35 pasien didapatkan hasil akhir setelah perawatan, 4 pasien $(11,4 \%)$ mengalami fraktur iga, 2 pasien $(5,7 \%)$ mengalami hemotoraks, dan 2 pasien $(5,7 \%)$ meninggal sedangkan 27 pasien $(77,1 \%)$ lainnya tidak mengalami komplikasi.

\section{SIMPULAN}

Data pasien trauma tumpul toraks nonpenetrans di IRDB RSU Prof. Dr. R. D. Kandou Manado periode Januari 2014 sampai Juni 2016 yang terbanyak pada tahun 2014 dan $2016(37,1 \%)$ dan yang paling sedikit tahun 2015 (25,7\%). Mayoritas pasien berusia 21-30 tahun, berjenis kelamin laki-laki dengan penyebab kecelakaan lalu lintas dan diberikan penanganan konservatif. Hasil akhir perawatan terbanyak trauma tumpul toraks non penetrans yang didapat di RSUP Prof Dr. R. D. Kandou Manado yaitu tanpa komplikasi.

\section{SARAN}

Perlu dilakukan perbaikan dalam penyimpanan dan penyusunan serta kelengkapan data rekam medik pasien di 
RSUP Prof Dr. R. D. Kandou Manado

Sebaiknya penelitian ini dilanjutkan dan diperluas pemahaman tentang trauma tumpul toraks

\section{DAFTAR PUSTAKA}

1. Sjamsuhidajat $\mathbf{R}$, de Jong $\mathbf{W}$, editors. Buku Ajar Ilmu Bedah (3rd ed). EGC. Jakarta. 2010, Hal. 121-122, 502-506

2. Al-Koudmani I, Darwish B, Al-Kateb K, Taifour Y. Chest trauma experience over eleven years period at $\mathrm{Al}-$ Mouassat University Teaching Hospital-damascus: A retrospective review of 888 Cases. Journal of Cardiothoracic Surgery 2012,7:35.

3. Paci M, Ferrari G, Annesi V, de Franco S, Guasti G, Sgarbi G: The role of diagnostic VATS in penetrating thoracic injuries. World Journal of Emergency Surgery 2006;1:30.
4. Novita L, Limpeleh H, Monoarfa A. Pola trauma tumpul toraks di Instalasi Rawat Darurat Bedah RSU Prof. Dr. R. D. Kandou Manado periode Juli 2011-Juni 2012. eCl. 2014;2(2),

5. Sitepu CE. Trauma toraks. 2008 (cited 30 Agustus 2016). Available from: http://repository.usu.ac.id/bitstream/123 456789/33158/4/Chapter\%20II.pd.

6. Manurung JRH. Kecelakaan Lalu Lintas. 2012 (cited 14 November 2016). Available from: http: //repository.usu.ac.id/bitstream/123456 789/34939/4/Chapter\%20II.pd.

7. Profil Kesehatan Indonesia 2015. Gambaran Departemen Kesehatan Republik Indonesia, 2015; p. 87. Available from: http://www.depkes.go.id/resources/dow nload/pusdatin/profil-kesehatanindonesia/profil-kesehatan-Indonesia2015.pdf. 